\title{
How to Use Multimedia in College English Vocabulary Teaching
}

\author{
Yujie Chang
}

School of Foreign Language, Zhengzhou University of Industrial Technology. China

\begin{abstract}
Keywords: multimedia; college English vocabulary teaching; vocabulary strategy.
\end{abstract}
\begin{abstract}
It is imperative to reform the existing college English vocabulary teaching methods due to the important role it plays and many of the problems existing to be solved in the vocabulary teaching. This paper discusses how to use multimedia in college English vocabulary teaching based on the analysis of the situation and problems of the current college English vocabulary teaching, as well as the laws of vocabulary learning and strategy.
\end{abstract}

\section{Introduction}

Vocabulary teaching is an important aspect of language teaching. The vocabulary acquired by students directly affects their development in listening, speaking, reading, writing and translating skills. Vocabulary mastery and application is a prerequisite for language learners to improve their English language skills, furthermore, vocabulary learning can promote the improvement of English proficiency. Nanchao (2005) put forward that multimedia technology can promote the vocabulary learning and his theoretical basis is that " In the process of second language acquisition, Chinese students learn vocabulary mainly by memory, and the use of multimedia teaching technology is able to enhance memory. Because the vocabulary memory is directly related to information input in the first place. Psychologist studies prove that people obtain information mainly through the auditory and visual stimuli, among which 11\% through the auditory and $83 \%$ through visual information. Multimedia technology can provide students with rich videos, images and texts, making their eyes and ears work together, and this is helpful for vocabulary identify and extract, thus promote the vocabulary teaching.

At present, English teaching in China is undergoing drastic transformations, which not only enriches the language input of English classroom teaching with expanding the amount of new words, but also promotes the implement of multimedia teaching in the classroom instruction. Especially for many universities, in order to adapt to big class teaching, they pay more attention to the application of multimedia technology and development due to years of enrollment expansion, increasing class sizes. As in "College English Curriculum Requirements" rules, requiring universities to actively promote and practice computer and multimedia assisted English teaching. However, the actual teaching effect is below expectation, this paper analyzes the current situation and problems of college English vocabulary teaching and discusses how to use multimedia in college English vocabulary teaching, combining with the laws of vocabulary learning and strategy.

\subsection{Current situation and problems of college English vocabulary teaching}

As the continuous expansion of college enrollment in recent years and the constantly deepening of the reform of English teaching, the English vocabulary teaching in many universities are facing pressure from various aspects and challenges. First of all, the increasing class size makes each student has less opportunity to participate in classroom language contact, which is not conducive to the students' language practice; Second, there are differences among various colleges in multimedia and campus network construction, so different colleges have formed different styles in making use of multimedia in college English teaching; Third, the limitation of class hour makes it more difficult for teachers to give high quality of English vocabulary teaching; Fourth, according to relevant investigation, the vocabulary grasped by China's students is too small when they entering colleges, but the "College English Curriculum Requirements" has made clear rules of vocabulary, this also make the English vocabulary teaching more difficulty; Fifth, the pressure of College English Band 4 
and Band 6 also prompts teachers to find a more effective way to carry on the college English vocabulary teaching.

\subsection{The current status and problems in the college English vocabulary teaching and learning}

The mentioned objective problems and pressure have put forward higher requirements to the college English teachers on "teaching". Some teachers start to research the characteristics of vocabulary teaching and the law of vocabulary learning, and further study how to create and improve English vocabulary teaching with Chinese characteristics. But many teachers still do not have a comprehensive understanding of the importance of vocabulary teaching. Many cannot make flexible and effective use of multimedia in vocabulary teaching for lack understanding of the multimedia technology. Also, they cannot have an overall understanding of vocabulary learning and teaching strategies, so that vocabulary teaching strategies and vocabulary assessment tests cannot be conducted effectively. What's worse, although the students do a lot in vocabulary learning, the result is not optimistic. Many students know that rote memorization is not a desirable vocabulary learning method, but they still use it unconsciously. Thus it is necessary to help them to master and use vocabulary learning strategies effectively.

\subsection{Vocabulary learning strategies}

English vocabulary learning strategies can be divided into three aspects: metacognitive strategies, cognitive strategies and social (emotional) strategy. Metacognitive strategy includes four parts: the learner's initiative, selective attention, self evaluation and self arrangement. Cognitive strategy consists of seven parts: repeat, speculation, context, imagination, dictionary, word formation and contact. Society (emotional) strategy includes two parts: social activity and emotional control.

In addition, as we all know, learning and mastering of vocabulary is a process of gradual accumulation and constantly improving. At the same time, the acquisition of vocabulary is inseparable with the learner's memory. Forgetting regularity of memory and reminded us to repeat and recreate new vocabulary, and the earlier your repeat the new vocabulary, the more possible will the new vocabulary words information stored in long-term memory.

The method of effectively using multimedia in English vocabulary teaching:

\section{Use Powerpoint to Improve English Vocabulary Teaching}

To learn English well, students must remember words. Words should not only be spelled letter by letter, but should be read and listened in accordance with the syllables words, thus students are gradually able to read and write. Words teaching cannot be isolated. Teacher should put the words in the picture on the slide, and teach the words in the scene, which is helpful for the students to understand them, thus words memorizing will get twice the result with half the effort. In this process, students will grave the words in mind with the help of vivid scene.

In addition, practice is essential to check students' mastery of course, and to consolidate the new learned lesson. Prepared powerpoint presentations can save the time of blackboard writing in classroom practice, can also make students repeatedly practice the key and difficult points. After each class, the teacher can put the common mistakes in homework on slides, and show how to correct them in class. In this way, teaching can be pertinent, instructive and conclusive, which can make the students have more time for exercise to learn more better, thus greatly improving the efficiency of classroom teaching.

\section{To Expand Students' Vocabulary by Creating Scenes Related to the Texts}

In English teaching, audio and video can effectively create English actual situation, which can develop the students' ability of thinking in images, the teaching effectiveness is obvious in this way. The core of creative thinking is to strengthen the students' curiosity and to inspire the students' imagination. In other words, students' ability of free association can be developed through a large number of interesting things, scenes and images on multimedia slide. It arouses students' thirst and 
curiosity for knowledge, on the other hand, it inspires the students' creative imagination and legend, strengthening their thinking in images.

Teachers can get good teaching results by creating certain situation and help students entry roles in teaching, for it is easy to arouse the students' emotional experience, to stimulate students' interest in motivation. There are many ways to create the scene, for example, putting a particular situation and the picture on multimedia slide, which reflects the text content, attracting students through vivid language, image and animation. When watching and listening, students try to figure out the meaning of the text, at the same time they also understand the meaning of words. Choose several students to role play the dialogue in the text at the appropriate time, turn off the voice system, thus the actor can be familiar with the pronunciation of words by reading the corresponding sentences.

\section{Make Full Use of Audio-Visual Function of Language Lab}

Advanced language lab is equipped with TV, camera and computer audio and video synchronization system. We can combine these intuitive teaching media with traditional teaching device, increasing the amount of information, adjusting the speed of stimulus and reflect, improving the repetition rate, this makes students solve the emphasis and difficulty in vocabulary during listening.

For example, we can choose a situation related to the teaching content, which is recorded in advance. In the scene there are more than two people, the more students participate in, the better, and then write the keywords in this section on the screen. Let the students determine their own performance according to the dialogue scenes, key words and their own imagination. After their performance, teacher can play the recorded dialogue, let they find out the deficiencies and advantages according to the sample, and correct the improper use of words. In this way, the whole class becomes the heaven and earth for students, through which, they can improve their listening, speaking and expand their vocabulary.

\section{Utilize Computer Subject Question Bank to Strengthen the Detection Method}

Exam is a detection method of teaching effects, so it is of great significance to use this method scientifically to check teaching, to know the master knowledge of students, to promote teaching and learning, to improve the quality of teaching .With the wide application of computer teaching in university, we can use the computer English question bank to service English teaching. As we accumulated English questions on computer, we should constantly updated and added question bank and build students' exam records, which is convenient to do comparative analysis at any time. In this way, we can accurately grasp the teaching situation in time, and timely adjust the structure of the teaching methods and teaching structure, improve the results of English teaching.

\section{Conclusion}

It should be realized that in the teaching activities, students are the main body as teachers play a leading role, and the multimedia technology is an auxiliary means to help receiving the intended teaching effect. We should fully understand the concept of innovation education especially that the modern education is only a means of teaching, rather than a purpose. When using multimedia in college English vocabulary teaching, teachers should try to hold effectiveness principle and to select those contents to make slide which are difficult to achieve by traditional teaching method but can be implemented on computer, and can make full use of its characteristics. We should fully exert the advantages of multimedia and strive to avoid its disadvantages in college English vocabulary teaching by constantly exploring, thus it can really work in teaching to optimize English vocabulary teaching. 


\section{References}

[1]. Du Qin. English Teaching Strategy[M]. Beijing: Foreign Language Teaching and Research Press, 2002.

[2]. Jiang Zheng. Secrets of English Words[M]. Beijing: China's International Broadcasting Publishing House, 1993.

[3]. Fang Kemin. Preliminary Detection of College English Vocabulary Teaching[J]. Journal of the Beijing Institute of Technology,2006, (10).

[4]. Luo Yaoguang. Multimedia Technology and New Teaching Model[J]. Media in Foreign Language Instruction. 2002, (4).

[5]. Ji Xiaojing. On the Application of Multimedia in Teaching Chinese as a Second Language[J]. Media in Foreign Language Instruction. 2002, (5). 